\title{
"Hablo de la gente en el mundo vibrando por una mariposa": conversando con Rafael
} Urretabizkaya

\section{Resumen}

Hina Ponce*

"Yo creo que la amistad, la infancia, el amor... son patrias. Uno es de donde está situado y a veces esos territorios no son físicos. Son espirituales o temporales"

Rafael Urretabizkaya.

"El San Martín que yo siento, tiene olor a pan casero, tardes pobladas de coltros, picadito en el potrero"

Israel Prieto.

En mayo de 2021 me contacté por primera vez con Rafael para proponerle este intercambio. Por Facebook y desde San Martín de los Andes respondió, casi de inmediato, para confirmar el encuentro. En estos tiempos pandémicos, la mediatización de la tecnología y de las redes no fueron el escollo sino la posibilidad para encontrarnos. Fue así que, en un ida y vuelta constante de mensajes y ante la inmensa generosidad de Rafael, esta entrevista se materializó. Su obra y su diálogo son cuasi un movimiento centrípeto hacia el cotidiano, pero sobre todo, hacia el afecto. Me encontré ante la escritura de lo mínimo, que es, al mismo tiempo, la invencible.

Rafael nació en Dolores, provincia de Buenos Aires, en 1963. Desde 1983 vive en San Martín de los Andes, en cuyos alrededores ha dejado andar su trabajo de docente y de escritor. Ha publicado diferentes géneros, entre los que podemos mencionar: Te agarro a la salida (cuentos, 1997); Aimé, en coautoría con Willie Arrúe (novela, 2000, cinco reimpresiones); Tita y Toto (cuentos, 1997); Carlito el carnicero (poesía, 2004 у 2013); Tierras de aventuras, con Emilio Urruty y Silvia Iparraguirre (cuentos, 2004); Teresa (cuento, 2007); Informe sobre aves y otras cosas que vuelan (poesía, 2011, reimpreso en 2014); La ruina (novela, 2013, reeditada en 2019 bajo el título En la ruina); Sarita y ese tipo (novela, 2016); Ñawpa Miní, con grabados de Pedro Hasperué (poesía, 2016); Nawpa Guasú (poesía, 2017); Vendrá un centro (poesía, 2018); y Vairoleto Pechito libertario (teatro de títeres, 2018).

A raíz de la investigación en el marco del desarrollo de mi proyecto doctoral, la entrevista se guió en torno a la lectura, como no al asedio, de la obra En la ruina. La novela camina por una serie de temas que se van tejiendo sin solaparse: de lado a lado, tenemos la alegría, la migración, la comunidad, lo diario que se imbrica con lo testimonial, con el relato oral, con la

\footnotetext{
Egresada de la Licenciatura en Letras Modernas, el Profesorado en Letras Modernas y la Tecnicatura Instrumental en Corrector Literario. Doctoranda en Letras. Estudiante de la Maestría en Didáctica de la Lengua y la Literatura, Escuela de Letras, Facultad de Filosofía y Humanidades, Universidad Nacional de Córdoba. hinaponce@gmail.com

Recibido 28/05/2021. Aceptado 01/06/2021.
} 
poética que nace del territorio vivido y que posee un espesor temporal y espacial. En ella los personajes principales construyen y reconstruyen el hogar, y ante las peripecias de sus viajes, siguen siendo "amigos a todo trapo" como dice el autor.

A continuación, los resultados de la serie de intercambios que compartí con Rafael.

H. P. ¿Qué sentido tuvo para vos el cambio de nombre de la novela de La ruina a En la ruina? ¿La preposición marca de alguna manera un situarse, corriendo el foco del objeto para ponerlo en el lugar, la forma de estar?

R. U. Estar y quedarse en ella. En la ruina. Es más preciso, claro. Esos amigos se mandan por aquí para dar vuelta la torta del reparto de las cosas del mundo. De su mundo, que viene bandeado de injusticia. De su mundo, que es parte del mundo que necesita ser cambiado, y ellos presienten que encontraron la manera de hacer su parte. Y de paso, con esta aventura, pueden seguir siendo amigos a todo trapo, que es la energía de sus asuntos. La amistad. Una forma de seguir jugando, de tener ese motor en el pecho, dos o tres corazones. Es decir, esa clase de asuntos que pueden ocurrir a quienes piensan en ellos y en el otre. Esa certeza de hacer las cosas bien. De habitar la alegría invencible de reparar algo de lo roto. Esto pienso ahora, por tu pregunta. En realidad, el cambio de nombre fue más misterioso que premeditado.

H. P. ¿Qué sentidos aportan, cómo se intersectan las nociones de identidad, territorio y juventud en la novela?

R. U. Identidad, territorio, juventud y agregaría la amistad, por sobre esto que decís, y al silencio lo pondría como escenario. Estas cosas se dan cuerda entre sí. Insisto que lo de la amistad iría un paso adelante. Siento que estos jóvenes quieren levantar la mirada junto a su gente. Pero que antes que nada son jóvenes y tienen demasiadas ganas de cagarse de risa, bailar, conocer otros lugares, personas, amar. Su pueblo sufrió un genocidio de parte del Estado argentino y la tarea puede aparecer muy despareja para un par de jóvenes que perciben esta situación con claridad. Instintivamente saben que les cae medio desmesurado dar esa batalla por el esclarecimiento y las consecuencias de ese esclarecimiento, pero que aquí y ahora (en la ruina), siendo felices y asistidos por la fuerza invencible de la amistad, son todo un dato de que no hay para nada un pueblo vencido.

Es como cuando una comunidad se renombra, como ocurrió hace pocos años aquí cerca. Deja de ser Puente Blanco para pasar a ser Payla Menuko. Los y las involucrados renombrados se reinstalan en el mundo. Para ellos y para los demás que se preguntan ¿por qué? Es decir, no es un cambio de sustantivo; se trata de un dato político. Sin duda político, porque un grupo de personas se han reunido para intentar salir juntos de un problema. Han desestimado el individualismo. Una comunidad se reconoce y se desentiende del nombre impuesto. Claro que es bello el nombre Puente blanco, tal vez demasiado, a la medida de la candidez esperada por un sector de la sociedad que insiste en mirar a un pueblo originario como si estuviera en una vitrina o, en todo caso, como un aspecto exotizado del paisaje a ser contemplado por turistas. 


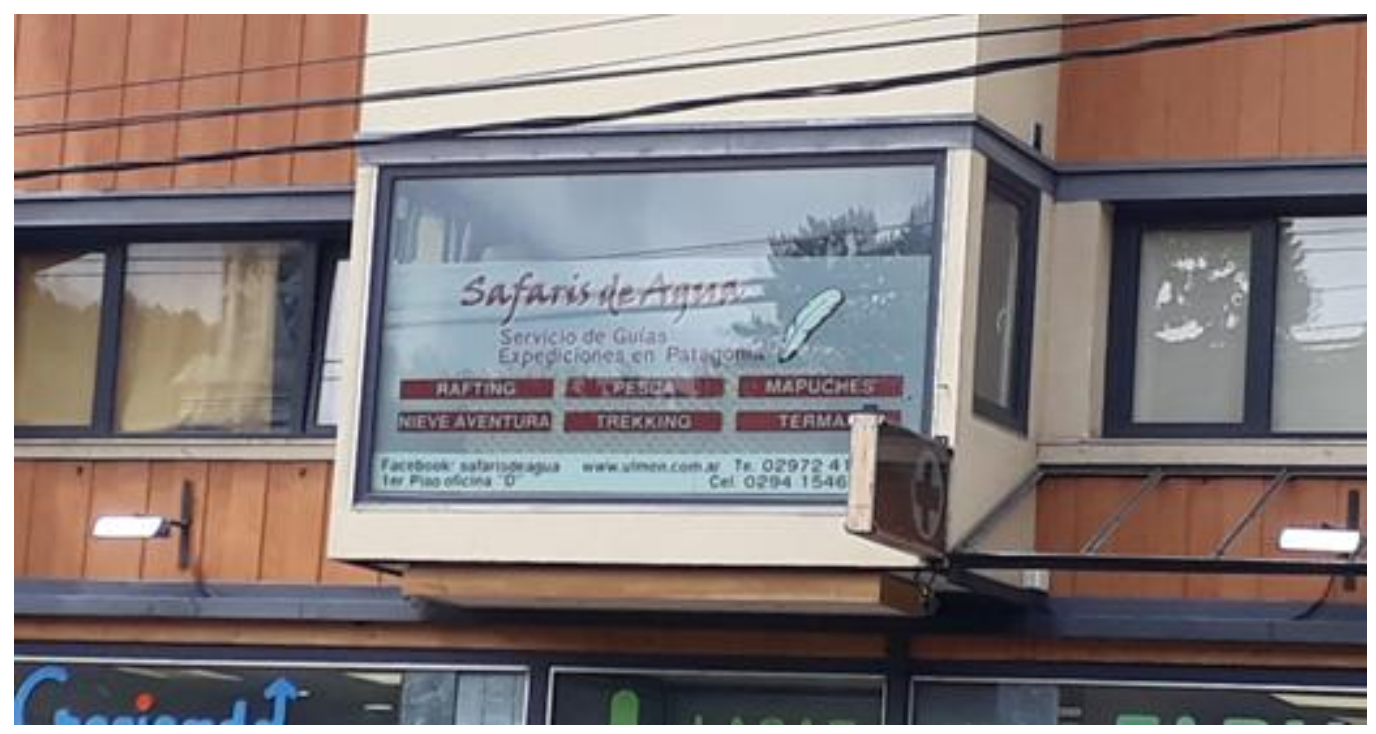

Esta es la vidriera de una agencia de turismo en San Martín de los Andes, hoy, en la avenida principal, frente a la Dirección de Turismo y a metros de la plaza. Ofrece "safaris de agua" y desmenuza que en esta expedición el turista tendrá, para su solaz, "rafting, pesca, mapuches, nieve aventura, trekking, termas".

H. P. La novela problematiza - o no- elementos que son cotidianos en la Patagonia: los mapuches urbanos que han migrado por diferentes motivos, el asistencialismo político, las dinámicas de poder. Entonces, ¿cómo se reconfigura, qué sentido tienen esas cuestiones en la tensión pasado/presente, memoria/testimonio?

R. U. Sí, es lo que vengo charlando en la pregunta anterior. Aparece porque está sin resolver y lejos de poder hacerlo, pero la sensación que prevalece es que se viene avanzando mucho.

No hay en la novela un gran discurso que lo problematice. Los protagonistas no saben tantas cosas; son jóvenes. Pero conocen la anécdota del tesoro escondido. Saben por qué su gente dejó ese tesoro para poder rajar del "malón huinca" más alivianada. Y sienten que la injusticia les cae muy incómoda. Todo esto sucede en su espacio territorial, "Quetal Quetal", y en la ciudad. Ellos conocen todo ese silencio de la comunidad, de las personas, ese tiempo que se da para entender. El silencio es, junto a ellos, un protagonista.

No nos olvidemos de que es el silencio quien hace posible la palabra. Y que la palabra propia, la que nombra, te pone en el mundo de manera invencible. Algo ronda de esto y algo se explicita, como en el capítulo 14:

Silencio destungado. Se hace un silencio largo. El silencio nunca es incómodo entre ellos. Estar callado no significa, como en otras partes, no tener respuestas. Silencio aquí significa silencio, rumiar las palabras, mandarlas para adentro, con las otras. Silencio de tener comentarios que no son respuestas. De tener respuestas que no cambian nada. Silencio para atesorar el orgullo, un cerquito a la dignidad, silencio, sabe y no contesta, sabe que lo que sabe también lo saben todos, silencio entonces que dice que el otro está hablando de más, silencio que señala con el dedo al Delegado y le dice charlatán, silencio que les dice al Delegado y a la capataza y al Político y a Adolfito y al destungado y a Enrica y a los otros de la cuadrilla que no cuadra que todos van a tener que tener de este silencio, llegado el caso; si es que son capaces, si se 
aguantan, si resisten cuando les llegue el momento de la atropellada del tiempo, o si en cambio se rinden y permiten que les baje una palabra, cualquier palabra que sea cual fuera de todas las invencibles o arrastradas palabras del mundo lo único que podrán significar, será un pedido de clemencia.

H. P. La lectura de la novela es completamente coral, en el sentido de que hay una narración en la encrucijada entre la oralidad y la escritura. ¿La planeaste así? ¿Es una forma de narrar que elegís?

R. U. Es una elección, claro. Pero, además, comparto mucho lo que dice Rodolfo Walsh, que "escribir es escuchar". Y aquí se juntan esta idea de Walsh con el hecho de que trabajé y viví varios años en las comunidades mapuche y criollas del sur de Neuquén. "Quetal Quetal" es, en gran parte, Huilqui Menuco, donde estuve 8 años. Toda la escena de cuando se pierden y tienen visiones sucede en un cañadón que conozco perfectamente, que tiene un inmenso friso de pinturas con miles de años de antigüedad, un mensaje, un libro, te diría, aunque es mucho más, desde los tiempos y hacia todos los tiempos por venir. Cuando digo inmenso, pensá en una pintura sobre una piedra de unos dos metros de alto por diez de largo.

Es una elección el modo de narrar y la primera persona reiterada, también. Pero también te digo que no estoy escuchando solo lo que propone ese lugar y ese momento. Llego ahí con Jack London y con su "Para encender un fuego"; con Wislawa Szimborska pensando "Las nubes" que no necesitan ser vistas para poder pasar; voy con mi viejo que está armando un Ford $\mathrm{T}$ en la terraza de su casa; con Víctor Pailacura que me lleva a conocer; con Don Herminio que mete la mano en una oveja y sabe si va a estar seco el próximo verano. Vamos todos. Voy con todos.

H. P. Sobre esto que me contás, hay un poco de esa zona liminar entre el arte y la artesanía. ¿Podés agregar algunas percepciones sobre este punto?

R. U. Sobre esto pienso dos cosas. Por un lado, siento que en el proceso de escribir hace síntesis la experiencia. Y el momento de la escritura llega acompañado de intuición y de confianza. Me parece que la intuición y la confianza son justamente la energía de la poesía. Cuando esto está andando, los textos tienen algo personal con la verdad, aunque transiten la fantasía. Esto es del mundo del oficio, en el sentido del trabajo. No digo que se tenga adquirido el oficio, digo en el modo de disponerse a la tarea. Arremangarse y vamos. Esta manera da y quita. Porque seguramente no se tiene la solidez de la formación en la disciplina, pero es justo por esto que a lo mejor se tendrá lo opuesto, es decir, la fragilidad. Y creo que la fragilidad y la conciencia de andar en la fragilidad pueden ser elementos interesantes para escribir en un mundo donde pocos quieren decir "no sé". Percibo que en la sociedad que vivimos la fragilidad es vista como debilidad, cuando es todo lo contrario. Esa certeza bolacera que sostiene a la amarreta pedagogía de la respuesta correcta y toda su asfixia, en oposición a la pedagogía de la pregunta y su viento de abajo lleno de vida.

Por otro lado, me viene algo de las escuelas. Hay una idea traída desde el constructivismo que habla de los saberes previos. Es muy fácil acordar con esto, pero he visto cómo, en ocasiones, termina siendo funcional a hacer poco en situaciones donde hay que hacer mucho y más que mucho, porque poco ya hay. Claro que es valioso que el abuelo sepa capar a diente, hacer una matrón con la memoria milenaria que baja desde el tiempo, o tener la habilidad de saber fabricar para iluminarse un sunchito con un frasco, un cachito de trapo y grasa de chivo, pero la verdad es que en el mundo ya existen montones de cosas más. Este abuelo valioso y necesario no podrá enseñar a ir al teatro, ni hablar de violines, de libros, del 
mar. Cosas del mundo y para todas las gentes del mundo. Esto de los saberes previos usado sin reflexión es funcional a que el otro siga chito ahí.

La novela esta traccionada con el tema del "coleccionista" que observa al otro y lo del otro con el deseo de llevarlo a su vitrina o a la vitrina del museo, en nombre de la ciencia. La historia que hace andar a En la ruina se va a resolver gracias a eso: los amigos deciden fabricar antigüedades para estos compradores ávidos de exclusividades. Puntas de flecha recién hechas, vasijas recién envejecidas. Elementos de gran inocencia comparados con los cráneos que coleccionaba el perito Moreno. Recordemos que cuando Moreno cuenta que tiene por fin la cabeza de Cipriano Catriel, lo hace de esta manera:

La cabeza sigue aquí conmigo; hace un rato que la revisé pero aunque la he limpiado un poco, sigue siempre con bastante mal olor. Me acompañará al Tandil porque no quiero separarme de esta joya, la que me es bastante envidiada.

H. P. Has dicho que esta es una novela sobre la amistad. Más allá de la relación intersubjetiva entre los personajes, ¿considerás que hay un vínculo de afecto con la Patagonia en la novela?

R. U. Amor profundo. Sí. Con la gente, sus paisajes, sus silencios, sus palabras, sus locuras, sus deseos, mis deseos, mis locuras. Estoy aquí, en Patagonia, con toda esta invitación de la estepa a pensarse con los otros y otras y en el mundo y en el tiempo. Me encanta la desmesura de la Patagonia; vivo en un lugar hermoso con bosque, ahora, estallado de otoño, pero me fascina Huilqui, Aucapán, Pilo Lil, Comodoro Rivadavia, Zapala. Lugares mucho más esteparios, habitados por esa distancia donde parece que no hay nada y resulta que hay todo. Donde vos no ves pero a vos te ven. Hasta que un día te ven y ves y, así, es posible existir.

Este lugar al que me traes con tu pregunta me da pensar en la palabra humus. De ella entiendo que vienen las palabras humano, humilde, húmedo. De ella viene, sin dudas, la palabra trashumante. Tan de los pueblos de esta zona, donde la gente viaja a la veranada con sus animales, para que tengan su alimento, y regresan a la invernada luego. Ir detrás de los mejores humus. Trashumar. Moverse para vivir.

Me da más pensar en la palabra humus que en Patagonia, entendida como recorte. Como de aquí hasta allá. Y mucho más lejano estoy de una idea de territorio como patria. Prefiero Laar a patria. Un pago donde quien llega es bienvenido como es. Donde valen más los gestos de afecto y pertenencia y cercanía que las banderas y los alambrados. Por otro lado, volvería a lo de trashumante (¡qué bella palabra!) en cuanto andar detrás de la mejor oportunidad para la vida, para el sustento y, en este sentido, poner en la escena nuestro joven país que declaró su independencia hace doscientos y poquito de años; hace 143 inició el genocidio sobre pueblos originarios del sur y que estos pueblos tienen más de 10000 a 12000 años desplazándose, por supuesto, a ambos lados de la cordillera de los Andes, hoy devenida en frontera política; en su momento, un puente. Trashumando.

H. P. En la novela hay una serie de construcciones de la otredad. ¿Quiénes son los otros? ¿Qué es la otredad? ¿Dónde se ubica? ¿Cómo funciona la experiencia de la extranjería en la novela?

R. U. No lo sé. Supongo que esa experiencia de cómo funciona es personal y es dinámica. Hay varias pertenencias y extranjerías dando vueltas. 
40. Las razas

- ¿Pero ahí no vive gente de otros lados?

- De otras comunidades a veces, pero toda gente de mi raza.

- ¿De tu raza?

— Yo la única raza que conozco es la de los que nos doblamos el lomo... y la otra.

Esto sucede en el capítulo 40.

Me haces pensar en la Carta a una profesora, ese libro maravilloso que escribieron los pibes de Barbiana. Llegados a esa pequeña aldea toscana trepada a la montaña (Italia, 1954), por ser los estudiantes que fracasan en los institutos de enseñanza oficial. Por una extraña coincidencia, son los pobres. Estos muchachos le escriben una carta a su profesora, expulsadora, que, en una parte, dice:

Si ustedes tienen el derecho en dividir el mundo en italianos y extranjeros les diré que yo no tengo patria y reclamo mi derecho a dividir el mundo en desheredados y oprimidos por un lado y privilegiados y opresores por el otro. Aquellos son mi patria, estos mis extranjeros.

H. P. De alguna manera hay tantas otredades como puntos de vista en la novela y fuera de ella. Con esta carta que traes, me parece que ese vínculo entre extranjeros/oprimidos tiene un poco que ver con la nueva representación de quienes habitan desde antes de la separación del territorio por parte de los Estados nacionales. ¿Te parece que se juega un poco, también, la extranjería en las migraciones internas? Pienso, por ejemplo, campo/ciudad.

R. U. Los amigos van a la ciudad porque quieren estudiar. Uno, de movida, va a parar a la obra y el otro, a la fotocopiadora. Pero habitan el lugar, son de ahí, cuando van a bailar, cuando conocen a su nuevo amigo. Ellos son de donde se pueden sentir bien, de donde pueden ser ellos. El patrón, cuando llega al asado en la obra, porque se puso el techo, lo hace tan desubicado que, aunque está en su obra, con los obreros que contrató, y aunque pagó el asado, es un perfecto extraño. Lo que lo vuelve un extranjero es su manera, no el hecho de ser el patrón, ya que podría ser uno bueno. El tipo está ahí, en la misma mesa que los obreros y sus familias, pero no está junto a ellos porque tiene el corazón en otro idioma.

H. P. ¿Cómo se construye el territorio en la novela? Y me remito a la cita: "El territorio no parece ser otra cosa que el lugar donde situar las preguntas que se van juntando. Y de ahí, tirar, tirar".

R. U. Se construye con deseos, imaginarios, proyecciones, con recuerdos. Pienso en cosas del estilo: dónde hacer el gallinero, poner en condiciones el día para llegar a un recodo del río donde se pesca mucho, regalarse el tiempo para escuchar a Don Aníbal, enamorarse de una persona y decírselo, aprender a andar en bici y salir a dar la vuelta a la manzana por primera vez, sacarse las rueditas, saludarse con los vecinos y vecinas, ayudar, ser ayudado, pasar una tormenta fuerte, ver llegar los pájaros que emigran, las bandurrias que se amigan con tu árbol 
y lo anidan, pedir fiado y que te den, fiar, hacer algún gol, perder, ganar, jugar a la escondida y quedar para lo último, picar piedra libre para todos los compas. Se construye de estos modos, me parece, agarrando equilibrio en un lugar donde nos conocen pelos y señales y donde sabemos si el viento de abajo trae lluvia o encula los pájaros o es bueno para jugar un picado en la canchita y para qué arco te conviene patear primero. El territorio es donde uno es.

H. P. La narrativa del viaje tiene una larga tradición en la Patagonia, sin embargo, ¿cómo se reformula el viaje, en este caso, el ojo que mira e, incluso, la voz que enuncia?

R. U. Los muchachos se mueven para saber quiénes son. Parece que viajan y vuelven, y se vuelven a ir, como hace el Panza Verde, para estar en el lugar que quieren estar, que es el de la felicidad de hacer lo que sienten que está bien. Aquí, diría que la justicia y las ganas de ser felices son su patria. Hay un gran trabajo por encontrar el tesoro y hacer La Ruina para que su gente viva bien. Trabajo grande que se le dispara a la épica, porque viven el gusto de hacerlo; no hay esfuerzo trabajoso porque no hay contradicción emocional.

H. P. Sabemos de tu labor docente rural. Cuando leí la novela, te pensaba como una especie de etnógrafo. Más allá de que la narración es ficción, ¿consideras que esa experiencia, o la experiencia de habitar la Patagonia, te da una forma particular de enunciar/escribir/estar?

R. U. Pienso que sí. Me siento afortunado. Pero, te digo, me encanta la gente, la vida, siento que podría vivir en cualquier lado no demasiado grande. Lo de las escuelas es la gran suerte de mi vida. Siempre fui un pibe bastante problemático como estudiante y un día se me presentó de pechito la posibilidad de volver a la escuela. Me fascinó. No podía directamente creer que la pedagogía se estudiaba. Y, claro, afortunado de aprender muchas cosas como esta que te comparto con Doralisa:

"Doralisa tiene 6 y a la escuela suele venir con regalos, se le nota de lejos cuando viene con dibujo. Brilla. El aula funciona en el puesto sanitario. Las cosas son así casi siempre. Puestos sanitarios que funcionan en aulas y a veces, al revés. Está bueno, tenemos pizarrón, balanza para pesar bebés, sillas, camilla. Doralisa viene con dibujo. Desde lejos se ve el brillo en sus cachetes, pero que digo, en los ojos, entera Doralisa trae dibujo que es la buena noticia de la vida.

Se acerca sin palabras toda sonrisa y me lo muestra. Es un conejo. Nos tomamos un ratito, se acercan otros compañeritos y compañeritas que van llegando. El conejo me recuerda otro de un libro que leímos hace poco y no me recuerda los que se pueden ver por aquí y como un salame verdadero le digo y pregunto: "Qué lindo. ¿Lo copiaste?”. Doralisa apaga la cara de todo placer y enciende una de aguda inteligencia con algo de pena y dice; "no maestro, $\mathrm{ME}$ LO CREÍ.

Doralisa de 6 años, en la mañana de Puente Blanco, enseña que CREER ES CREAR."

O esta, de Don Herminio de Pilo Lil:

"Mete las manos en el vellón de la oveja. Ahí deja los dedos, los remueve un poco. La oveja se impacienta, luego se calma. Mira la nada. Suelta la vista al horizonte del modo que saben hacer algunas personas, como don Herminio, y que es, en realidad, tan parecido a mirarlo todo.

Las manos registran si la lana tiene poco o mucho veri, que es esa condición que tiene la lana, así, como pegajosa y que hay que lavar varias veces; los dedos se mueven diestros y reconocen si tiene semillas y cuáles, si tiene espinas, qué olor tiene. Don Herminio se los mira, los huele. Mete las manos otra vez en la oveja, diría que hay un libro para él, en el vellón, pero me quedo corto. No busca las palabras, se nota que lo encuentran nomás y 
comienzan a salir de su boca como la novedad del mundo: Va a estar seco el verano. Vamos a salir para la veranada un poco antes o los animales van a rumbear solos. El río va a estar bajo, vamos a levantar temprano la leña que nos trae, si no el trabajo será el doble. Poco ventoso va a estar, los animales grandes van a andar poco resabiados, buen tiempo para amansar un potro y malo para trabajar con el Tengo y el Bandera, la yunta nueva de bueyes.

Saca las manos de la oveja enciclopedia, las pone otra vez en la pala con la que viene zanjeando un hilo de agua, desde una vertiente allá.

Pienso en el valor invencible del saber popular. La maravilla de tener una biblioteca en una oveja. Pero también pienso en que hay libros y que son para todos, también para Don Herminio. Son un logro de la raza humana, como una vacuna, un violín, la suela de goma de la alpargata reemplazando el yute que las hace bigotudas; como un cuadro, un avión... un vellón de lana."

H. P. Escuchar/escribir: ¿cómo funciona esa dualidad en tu experiencia?

R. U. No lo sé. Quién sabe cómo funcionará. Realmente no tengo idea de montones de cosas. Sí puedo dar cuenta de una voz interior que, cuando escribís, se larga a decir y decir. Cuando esto me sucede, suelto la piola para que esa voz diga todo lo que quiera, se mande. No estudié letras, por eso no puedo decirte mucho más. Sí me encantan los libros. Y cuando escribo no pienso en los géneros, menos en algunos detalles más finitos que estás preguntándome. De chico vi que mis padres tenían un asunto tremendo entre manos, entre las manos precisamente. Y pasé rápidamente de la etapa de creer que mis padres no sabían nada a manotearle los libros como el dedicado de Juanele Ortiz que se extravió, el de Machado, García Lorca, los Pablos —en especial, Pablo de Rokha—, Nicolás Guillén.

\section{H. P. ¿Considerás que hay una forma de narrar particularmente patagónica?}

R. U. Debe haber algo de eso. Durante varios años, por algunas cosas azarosas, participé reiteradas veces de encuentros literarios, ferias del libro y esos asuntos en poblaciones del sur de Chile, que me queda más cerca que Neuquén capital. Ahí sentí, de movida, que había una voz, una forma de. Luego, con el tiempo, tuve y tengo la suerte y la oportunidad de interactuar y leer a muchas y muchos, sobre todo, poetas de ambos lados de la cordillera. A veces, quien escribe (retomando la idea de Walsh de que escribir es escuchar) está más escuchando su tiempo, su barrio, qué hay en las ollas, en las paradas de cole, a qué juegan los pibes; y, a veces, está más en el íntimo y válido escucharse. Creo que cuando se impone más este escucharse se expande el territorio. Claro que no hablo de los regionalismos; me parece que eso es otro asunto. Hablo de qué cosa escucha quien escribe frente al acontecimiento del mundo, y hablo de la gente en el mundo vibrando por una mariposa, un despido, un desamor, un gol de cabecita, fideos con manteca, una noticia fulera en la doctora, el viento que tiró la ropa de la cuerda, un plato de comida que se enfría para toda la vida, una sonrisa a la hora exacta.

Entre San Martín de los Andes y Córdoba, mayo de 2021. 